\title{
PERBAIKAN FINISHING PRODUK OLAHAN KAYU JATI BAGI PENGRAJIN LOKAL DI KOTA KUPANG
}

\author{
Jahirwan Ut Jasron'1), Nixon Rammang'2), Adi Yermia Tobe'1), Arifin Sanusi1) \\ 1)Program Studi Teknik Mesin, Fakultas Sains dan Teknik, Universitas Nusa Cendana, Kupang, NTT, Indonesia \\ ${ }^{2)}$ Program Studi Kehutanan, Fakultas Pertanian, Universitas Nusa Cendana, Kupang, NTT, Indonesia \\ Corresponding author : Jahirwan Ut Jasron \\ E-mail : jahirwan.jasron@staf.undana.ac.id
}

\section{Diterima 24 Novemebr 2021, Direvisi 10 Desember 2021, Disetujui 10 Desember 2021}

\begin{abstract}
ABSTRAK
Permasalahan utama yang dihadapi kelompok pengrajin Airnona dan Sikumana adalah kurangnya pengetahuan dan keterampilan dalam mengerjakan finishing pada produk olahan kaju jati yang mereka geluti. Mencermati permasalahan tersebut, maka perlu dilakukan edukasi dan pelatihan tentang berbagai metode finishing pada produk hasil kerajinan. Kegiatan pengabdian kepada masyarakat ini bertujuan untuk memberikan pengetahuan dan mengasah keterampilan para pengrajin tentang proses finishing produk olahan kayu jati. Dalam kegiatan pengabdian ini menggunakan metode ceramah dan diskusi dilanjutkan dengan praktek finishing produk yang difokuskan pada jenis aplikasi milamin. Setelah Kegiatan pengabdian ini selesai dilakukan, diharapkan peserta pelatihan mengetahui salah satu metode finishing yang baik dan mampu mengaplikasikanya. Ada empat tahapan yang dilakukan dalam kegiatan pengabdian ini, yaitu: kegiatan persiapan yang meliputi diskusi kebutuhan pengrajin, kegiatan manufacturing yaitu mempersiapkan modul produk yang akan difinishing, kegiatan pelatihan finishing produk yang berhubungan dengan aplikasi milamin, dan kegiatan pelatihan manajemen yang meberi wawasan kepada pengrajin tentang tata cara pencatatan dan pengelolaan keuangan. Dari hasil evaluasi terhadap kegiatan pengabdian yang telah dilakukan terlihat bahwa pengetahuan peserta pelatihan terhadap proses finishing produk olahan kayu jati semakin meningkat dan telah mampu mengaplikasikan jenis finishing milamin pada produk olahan dengan baik dan benar. Dari hasil pencatatan keuangan terlihat ada kenaikan penghasilan pengrajin setelah pelaksanaan kegiatan pengabdian ini. Pengrajin berharap ada kesinambungan kegiatan seperti ini dimasa yang akan datang.
\end{abstract}

Kata Kunci : kayu jati; finishing; pelatihan.

\begin{abstract}
The main problem faced by the Airnona and Sikumana craftsman groups is the lack of knowledge and skills in finishing the processed teak products they are involved. Observing these problems, it is necessary to conduct education and training on various finishing methods on handicraft products. This community service activity aims to provide knowledge and hone the skills of artisans about the process of finishing teak wood products. This service activity uses the lecture and discussion method followed by product finishing practices focused on melamine application. After this service activity is completed, it is hoped that the trainees will know one suitable finishing method and apply it. There are four stages carried out in this service activity, namely: preparation activities which include discussing the needs of artisans; manufacturing activities, namely preparing product modules to be finished, product finishing training activities related to melamine applications, and management training activities that provide insight to artisans about procedures for recording and managing finances. From the results of the evaluation of the service activities that have been carried out, it can be seen that the trainees' knowledge of the finishing process of processed teak wood products is increasing, and they have been able to apply the type of melamine finishing to processed products correctly and adequately. From the results of financial records, it can be seen that there is an increase in the income of artisans after implementing this service activity. The craftsmen hope that there will be continuity of activities like this in the future.
\end{abstract}

Keywords: teak wood; finishing; training.

\section{PENDAHULUAN}

Usaha kerajinan kayu jati merupakan

salah satu bentuk usaha yang cukup menjanjikan karena merupakan usaha yang menghasilkan produk kebutuhan masyarakat luas. Selain menghasilkan produk yang bernilai fungsional, kerajinan ini juga sangat erat kaitannya dengan nilai estetika. (Hidayat, 
2020),(Hermawan dkk., 2013), (Puspita dkk., 2016).

Untuk menghasilkan produk-produk yang berbobot serta bernilai estetik yang tinggi, sangat dituntut kreativitas dari para pengrajin. Salah satu faktor penting yang harus dikuasai oleh pengrajin adalah kemampuan finishing produk terutama dalam hal pengecatan.(Kurniawan dkk, 2013), (Lestari dkk., 2016)

Sejalan dengan perkembangan teknologi industri mebel, maka teknologi finishing produk mejadi penting untuk menghasilkan berbagai variasi tampilan akhir sebuah produk olahan. Selain itu finishing produk yang baik akan meningkatkan nilai jualnya dan menurut hasil kajian diperoleh bahwa finishing produk yang kurang baik akan menurunkan nilai jual hingga kurang lebih $40 \%$. (Premono dkk., 2007), (Rispawati \& Suryaningsih, 2021), (Gunadi, 2021)

Beberapa jenis finishing yang sering diaplikasikan pada kerajinan kayu jati, antara lain; politur,cat duko, melamine transparan, melamine bernuansa marmer, melamine bernuansa granit, melamine bernuansa fulkanik, finishing berbahan pengencer air, dan masih banyak lagi ragam jenis dan bahan untuk finishing produk olahan tersebut.(Darmono, 2013).

Pada umumnya pengrajin kayu jati di Kota Kupang berasal dari Kota Jepara. Namun karena permintaan produk mebel yang sangat meningkat maka mulai banyak pengrajin lokal yang tertarik untuk menggeluti usaha kerajinan kayu jati. Perkembangan ini tentunya perlu diikuti dengan mengupayakan adanya transfer teknologi perbaikan finishing produk olahan kayu jati dari pengrajin jepara kepada pengrajin lokal. Mengingat kualitas produk yang akan dijual harus terjamin kualitasnya baik sebagai komoditas domestik ataupun komoditi ke luar negeri yang tentunya memiliki aturan yang ketat mulai pengolahan bahan mentah sampai produk jadi.

Perkembangan Kerajinan Jati di Kota Kupang tentunya ditunjang oleh keberadaan bahan baku jati yang masih banyak di hutan di Pulau Timor khususnya dan di seluruh pulau di Nusa Tenggara Timur umumnya. Hal tersebut nampak dari perhatian pemerintah dalam menjaga kelestarian hutan jati. Luas wilayah Provinsi Nusa Tenggara Timur : Daratan :

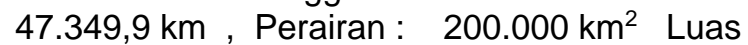
Kawasan Rutan Provinsi NTT: $1.808 .990 \mathrm{Ha}$ (38,21\% dari wil daratan).

Berdasarkan hasil wawancara, permasalahan mendasar yang dihadapi oleh kelompok pengrajin lokal di kota Kupang adalah mereka belum pernah mendapatkan pelatihan formal mengenai pengolahan kayu jati secara khusus pengetahuan tentang proses finishing produk olahan. Karena itu tujuan utama dari kegiatan ini adalah dengan diterapkannya teknologi finisihing produk olahan maka kelompok usaha mitra akan mencapai (1) Aspek Produksi ; peningkatan omset dari kelompok usaha karena meningkatnya pengetahuan dan keterampilan mereka tentang macam-macam teknik finishing yang menentukan kualitas dari produk olahan. (2) Aspek Manajemen ; Pengrajin lebih mampu merencanakan dan mengatur administrasi usahanya, karena meningkatnya skala operasi produksi sehingga diperlukan pengelolaan sistem keuangan, sistem produksi, dan sistim administrasi.

\section{METODE}

Untuk memecahkan permasalahan yang dihadapi oleh khalayak sasaran dalam kegiatan pengabdian mengikuti beberapa tahapan sebagai metode pemecahan sebagai berikut :

\section{Tahapan persiapan}

Pada tahapan ini pelaksana kegiatan melakukan pendekatan dan pengumpulan data dan informasi awal berhubungan dengan tujuan pelaksanaan kegiatan. Selain itu juga diidentifikasi kemampuan dasar Teknik finishing dari seluruh karyawan mitra kegiatan.

\section{Tahapan Pelaksanaan}

Setelah dilakukan rapat dan diskusi serta pengumpulan data awal, dilanjutkan dengan tahapan pelaksanaan kegiatan yang menggunakan beberapa pendekatan kegiatan yaitu :

\section{a. Ceramah dan Diskusi}

Metode ini dipilih untuk menyampaikan teori dan konsep substansi yang sangat prinsip dan penting yang harus dikuasai oleh para peserta pelatihan dalam finishing produk olahan kayu jati. Permasalahan yang disampaikan dalam metode ini meliputi:

(1) Persiapan benda kerja (penghalusan permukaan kayu yang akan difinishing);

(2) Teknik penutupan pori kayu;

(3) Teknik pemberian lapisan; dan

(4) Teknik aplikasi pelapisan akhir.

b. Demonstrasi

Metode demostrasi sangat penting artinya untuk mencapai keberhasilan pelatihan sebab dalam tahap pelatihan suatu proses kerja akan dapat dengan mudah diikuti dan dipraktekan oleh peserta pelatihan apabila keterampilan pokok tersebut diperagakan dengan baik khususnya dalam hal:

(1) Mempersiapan permukaan benda kerja;

(2) Teknik penutupan pori kayu dengan wood filler; 
(3) Teknik pemberian lapisan dasar pada benda kerja; dan

(4) teknik aplikasi pelapisan akhir pada benda kerja sesuai dengan dengan berbagai alternatif pilihan seperti clear gloss, clear dof, atau semi gloss.

\section{c. Latihan dan Praktek}

Metode ini bertujuan untuk memberi bekal keterampilan yang optimal bagi para warga belajar. Dalam metode ini, peserta dilatih untuk melakukan sendiri atau mempraktekkan dengan cara menirukan sesuai dengan demonstrasi yang dilakukan oleh instruktur yang memang telah terbukti keberhasilannya. Kegiatan praktek ini kadang kala perlu diulang berberapa kali agar para warga belajar mempunyai kompetensi dalam pekerjaan finishing produk olahan kayu jati.

Materi praktek yang harus dilakukan dan dikuasai oleh warga belajar adalah semua tahapan kerja dalam finishing warna transparan dan semi transparan. Untuk mendapatkan hasil keterampilan yang tinggi maka warga belajar harus membuat berbagai motif transparan (natural) dan semi transparan termasuk mengaplikasikannya pada benda jadi yang berupa meja, dan pintu.

\section{Tahapan monitoring dan evaluasi}

Tahapan monitoring dilaksanakan untuk memastikan seluruh materi dan praktek yang sudah diberikan telah mampu dikuasai oleh mitra dan mengidentifikasi kemungkinan masalah-masalah baru yang timbul agar segera dapat diselesaikan. Pelaksanaan evaluasi dilaksanakan dengan pemeriksaan produk hasil penerapan aplikasi finishing yang dikerjakan oleh mitra dan diperiksa berdasarkan standar mutu hasil produksi.

\section{HASIL DAN PEMBAHASAN}

Sesuai dengan tahapan pelaksanaan kegiatan yang sudah direncanakan maka hasil kegiatan yang sudah dikerjakan adalah sebagai berikut :

\section{Kegiatan Awal}

Pada tahapan ini pelaksana kegiatan melakukan berbagai persiapan seperti pengaturan waktu pelaksanaan kegiatan pelatihan finishing produk dan manajemen usaha dan penyiapan tenaga ahli yang bisa menjadi nara sumber. Kegiatan persiapan ini meastikan tersedianya semua bahan yang diperlukan. Berdasarkan hasil diskusi dengan kelompok usaha disepakati jenis produk olahan yang akan diberi perlakuan finishing adalah produk olahan jenis mebel.

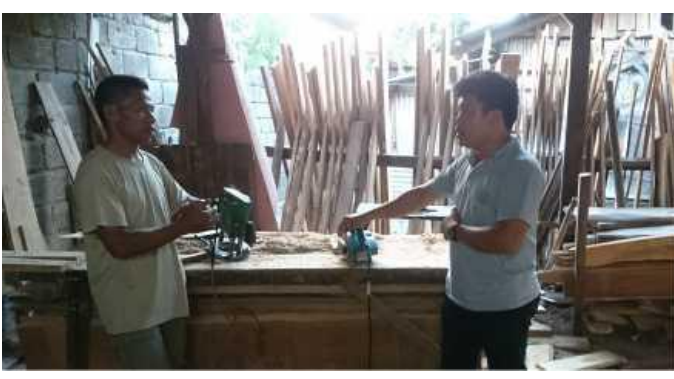

Gambar 1. Kegiatan persiapan

(Sumber : Dokumentasi Kegiatan)

\section{Kegiatan Manufacturing}

Pada tahapan ini pelaksana kegiatan melalukan proses pembuatan contoh finishing produk. Contoh produk mebel yang digunakan adalah daun pintu ukuran standar. Proses manufacturing ini bertujuan untuk mempersiapkan permukaan produk olahan agar siap untuk proses finishing, Adapun langkah-langkah pengerjaannya adalah :

a. Memeriksa seluruh permukaan benda kerja dan menganalisa jenis kerusakan bahan yang dibutuhkan untuk penyempurnaan.

b. Melaksanakan proses perbaikan yang membutuhkan pengeleman dan perbaikan permukaan substrat kayu.

c. Mengampelas permukaan benda kerja sampai halus. Gunakan sanding block bila mengampelas permukaan yang rata. Gunakan kertas ampelas secara bertingkat dari yang kasar ke lebih halus.

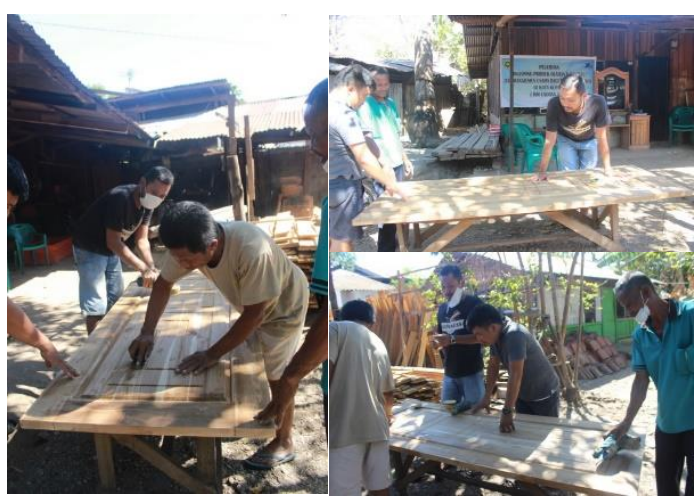

Gambar 2. Kegiatan Manufacturing

(Sumber : Dokumentasi kegiatan)

\section{Kegiatan Pelatihan Finishing Produk}

Pada tahapan ini tim pelaksana kegiatan melakukan proses pelatihan finishing produk yang diikuti oleh 4 orang tenaga kerja mitra. Jenis metode finishing yang diberikan dalam pelatihan ini adalah metode pengecatan melamin. Proses finishing produk ini mengikuti langkah-langkah sebagai berikut :

1. Menutup pori-pori dengan wood filter.

(a)Mengencerkan wood filler dengan thinner. 
(b)Menguaskan wood filler, bersamaan dengan itu lakukan pengebalan dengan majun dengan teknik melingkar sampai semua noda wood filler bersih dari permukaan kayu.

(c)Menguaskan warna dengan kuas kemudian ratakan warna.

(d) Melapisi/menyemprot lapisan dasar dengan sanding sealer (NC) Melamine Sanding Sealer (ML).

(e)Melapisi/menyemprot top coat (lapisan terakhir) dengan meuble lack/melamine lack.

(f) Poleskan bahan kompon pada permukaan benda lalu gosoklah dengan tekanan sedikit dengan kain lap. Melakukan pengomponan seluruh permukaan benda secara merata sehingga permukaan halus mengkilap dan bersih.(Fatori, 2013)

Dari hasil pelatihan ini para peserta ternyata telah mampu mengaplikasikan metode dengan baik walaupun masih diperlukan proses pendampingan untuk terus memperbaiki hasil finishing produk yang lebih baik. Dari hasil tukar pikiran dengan mitra ternyata mereka berharap kegiatan pengabdian dan transfer ilmu seperti ini harus berlanjut berhubung teknologi finishing produk terus berkembangsehingga mereka dapat mengikuti perkembangan teknologi finishing secara berkelanjutan.

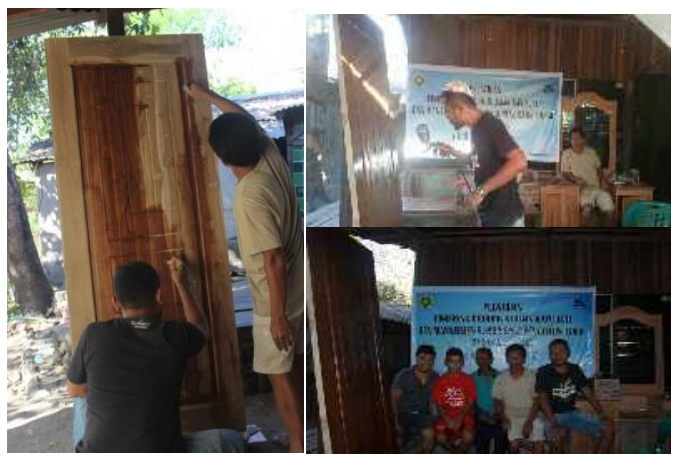

Gambar 3. Kegiatan Pelatihan Finishing (Sumber : Dokumentasi Kegiatan)

\section{Kegiatan Pelatihan Manajemen.}

Untuk kegiatan pelatihan manajemen usaha dilatih 2 orang tenaga kerja sekaligus pemilik usaha dimana dalam pelatihan tersebut disampaikan tata cara pembukuan yang baik yang tercatat dalam buku keuangan maupun dengan bantuan computer. Mitra berpendapat bahwa pelatihan manajemen usaha ini sangat bermanfaat karena selama ini usaha yang mereka lakukan masih sebatas usaha keluarga yang tidak berpatokan pada prinsip ekonomi sehingga sulit untuk mengetahui perkembangan keuangan usaha yang mereka geluti.

\section{SIMPULAN DAN SARAN}

Berdasarkan hasil pelaksanaan program kegiatan diperoleh kesimpulan sebagai berikut.

a. Produksi olahan kayu jati yang dikembangkan oleh pengrajin di Kelurahan Airnona dan Kelurahan Sikumana adalah pembuatan mebel dari bahan kayu jati lokal serta teknik finishing dengan motif sesuai dengan bahan dasar mebel tersebut yang bertujuan untuk meningkatkan kualitas produk olahan kayu jati yang dihasilkan.

b. Secara umum para pengkrajin kayu jati di Kelurahan Airnona dan Kelurahan Sikumana sangat berminat mengikuti pelatihan usaha produksi mebel kayu, khususnya pembuatan mebel yang difinishing dengan teknik finishing dengan bahan melamin.

c. Secara umum pelaksanaan program kegiatan ini tidak ada hambatan yang berarti. Namun, bila ditinjau dari aspek pemasaran produk mebel kayu dengan teknik finishing berbagai motif yang dihasilkan, mereka masih memerlukan bimbingan dan pembinaan lebih lanjut secara kontinyu.

\section{UCAPAN TERIMAKASIH}

Terimakasih kami haturkan kepada Pengrajin kayu jati Airnona dan Sikumana yang telah membantu menyukseskan kegiatan PKM ini, serta tentunya juga kami tidak lupa sampaikan pula ucapan terimakasih kepada Rektor Universitas Nusa Cendana dan LPPM Universitas Nusa Cendana Kupang yang telah membantu dalam pendanaan kegiatan PKM ini.

\section{DAFTAR RUJUKAN}

Darmono. (2013). Aplikasi Teknik Multivariate. Inotek, 14(2), 209.

Fatori, M. (n.d.). Finishing Konstruksi Kayu Jilid 2.

Gunadi, W. (2021). Prospek Dan Strategi Bersaing Pada Industri Furniture Berbahan Baku Kayu Jati. 11(1), 48-62.

Hermawan, I., Setiadi, T. A., \& Gunadi, K. (2013). Tinjauan Bentuk dan Konstruksi Mebel Jepara. Jurnal Rekajiva Jurnal Online Institut Teknologi Nasional CDesain Interior Itenas /, 01(02), 1-14.

Hidayat, J. (2020). Desain Hijau: Pemanfaatan Limbah Kayu Jati untuk Desain Furnitur Naratif dengan Aplikasi Finis Ramah Lingkungan. Visual, 14(2), 31-40. https://doi.org/10.24912/jurnal.v14i2.4509

Kurniawan, A., Supomo, H., \& Soejitno. (2013). Studi Pemilihan Jenis Coating Pada Komposit Bambu Laminasi Sebagai Material Lambung Kapal. Jurnal Teknik Pomits, 2(1), 1-5.

Lestari, A. T., Darmawan, I. W., \& Nandika, D. 
(2016). Pengaruh Kondisi Permukaan terhadap Daya Lekat Lapisan Pelindung ( Effects of Surface Conditions on the Adhession Strength of Surface Coatings ). J. IImu Teknol. Kayu Tropis, 14(1), 11-22. http://ejournalmapeki.org/index.php/JITK T/article/view/7

Premono, B. T., Ulya, N. A., Martin, E., \& Nopriansyah, A. (2007). Kajian Ekonomi Pengolahan Jati di Kabupaten Lampung Timur. Info Sosial Ekonomi, 7(4), 245-259.

Puspita, A. A. P. A., Sachari, A., \& Sriwarno, A. B. (2016). Dinamika Budaya Material pada Desain Furnitur Kayu di Indonesia. Panggung, 26(3), 247-260. https://doi.org/10.26742/panggung.v26i3. 189

Rispawati, D., \& Suryaningsih. (2021). ANALISIS PENINGKATAN EKSISTENSI PROMOSI PEMASARAN PRODUK MEBEL/FURNITURE DI TENGAH PANDEMI COVID - 19 PADA UD. MABRUK MATARAM. Jurnal Inovasi Penelitian, 2(2), 443. 